\title{
Fluorescent X-ray Analysis of Iron Ore and the Like by Glass Bead Technique*
}

\author{
By Hideshi SATO**
}

\section{Synopsis}

The glass bead technique is recently applied to the analysis of iron ores. Fluorescent X-ray Analysis Subcommittee of the Iron and Steel Analysis Committee, Joint Research Society in the Iron and Steel Institute of Japan studied the utility of this method with co-operative test. The results showed good accuracy and precision. This method has been established as ISIJ method. ISIJ method and its progress are described in this paper.

\section{Introduction}

The glass bead technique described in this paper is designed for preparing a glass bead by fusing such an oxide sample as iron ore with sodium borate or lithium borate for the analysis with the X-ray spectrometer. In this method, the fused sample is solidified into a bead as it is cooled, which is then subjected to fluorescent X-ray analysis.

In the steel industry, many efforts have been made on the fusion technique for the oxide sample since fluorescent X-ray analysis was first introduced, and no less than 21 papers on this subject have been delivered to the Fluorescent X-ray Analysis Subcommittee. With the development of the platinumgold (rhodium) crucible, it has become much easier to make glass beads and the practical usefulness of the fusion technique has been greatly enhanced. Coupled with the demand for the improved operational efficiency in the industry, this technique has found acceptance in many fields. Under these circumstances, it was decided that this Subcommittee should undertake the study of the glass bead technique for iron ore and the like, and an analytical method was drafted which also included the results of several series of the co-operative interlaboratory tests conducted in accordance with the resolution of this Subcommittee. This paper is a report of this analytical method which was approved at the 38th Meeting of the Iron and Steel Analysis Committee, Joint Research Society, ISIJ held in May, 1976.

\section{Problems to be Investigated in This Method}

Since similar techniques have been employed in many laboratories and institutes, it was necessary to have a correct understanding of the problem of how to generalize techniques used in these laboratories. Thus a project of co-operative interlaboratory tests was undertaken, using the same samples but leaving other conditions optional in each laboratory. Major experimental conditions adopted in eleven laboratories which participated in this project are shown below.
Fusing flux:

No. of Lab.

Sodium borate anhydride $\quad 9$

Lithium borate anhydride 1

Commercially available fusing mixtures 1

Sample-to-fusing flux ratio: $1: 7 \quad 1$

$\begin{array}{ll}1: 10 & 5 \\ 1: 15 & 5\end{array}$

Casting:

$$
1: 15 \quad 5
$$

Same crucible for fusion and casting (combination type)

Separate crucibles for fusion and casting (separate type)

Heating device:

Gas burner

High frequency (HF) induction furnace 1

Heating time:

HF induction furnace $3 \mathrm{~min}$

Electric furnace \& gas burner $10 \sim 20 \mathrm{~min}$

Stirring: One to several times in each fusion

As can be seen above, detailed operational conditions were varied from one laboratory to another. To put these different types of problems in right perspective, it was decided to study (1) the fusing flux, (2) the removing additive for the glass bead, (3) segregation in the bead, (4) effect of cobalt added on the determination of iron in iron ore, and (5) reproducibility of the glass bead.

\section{Study of Fusing Flux in Terms of X-ray Intensities}

The relative $\mathrm{X}$-ray intensities of elements to be measured were calculated in such cases that $\mathrm{Na}_{2} \mathrm{~B}_{4} \mathrm{O}_{7}$ and $\mathrm{Li}_{2} \mathrm{~B}_{4} \mathrm{O}_{7}$ fusing fluxes and commercially available fusing mixtures were used. The fluorescent X-ray intensity, $I_{i}$, of the element, $i$, is expressed by Eq. (1) when the secondary excitation is ignored.

$$
I_{i}=K \cdot W_{i} \int_{\lambda_{m}}^{\lambda_{e}} \frac{Q_{i}(\lambda) I_{\mathbf{0}}(\lambda)}{\mu(\lambda) / \sin \alpha+\mu(i) / \sin \beta} d \lambda
$$

where, $\quad \alpha$ : the angle of incidence of primary $\mathrm{X}$ ray

$\beta$ : take-off angle of fluorescent X-ray

$Q_{i}(\lambda)$ : exciting efficiency of a wavelength $\lambda$

$\lambda_{m}:$ the shortest wavelength of primary $\mathrm{X}$ ray

$\lambda_{e}:$ absorption edge wavelength of element, $i$

$\mu(\lambda)$ : mass absorption coefficient of the

* Originally published in Tetsu-to-Hagané, 63 (1977), 1200, in Japanese. English version received January 13, 1978.

** Chairman, Fluorescent X-ray Analysis Subcommittee, Iron and Steel Analysis Committee, Joint Research Society, ISIJ; Product R\&D Laboratories, Nippon Steel Corp., Fuchinobe, Sagamihara 229. 
glass bead with respect to wavelength, $\lambda$

$\mu(i)$ : mass absorption coefficient of element, $i$, with respect to the measuring X-ray

$W_{i}$ : concentration of element, $i$, in the glass bead

$I_{0}(\lambda)$ X-ray intensity of primary X-ray having a wavelength, $\lambda$.

Here it is difficult to obtain exact values of wavelength distribution of primary X-ray, $I_{0}(\lambda)$, and exciting efficiency, $Q_{i}(\lambda)$. If primary $\mathrm{X}$-ray is assumed to be composed of the absorption edge wavelength for the ease of calculation, $\mu\left(\lambda_{e}\right)$ nearly equals $\mu_{i}$ and Eq. (1) is expressed as follows.

Table 1. Ratio of fluorescent X-ray intensities in the three kinds of fluxes

\begin{tabular}{l|lllll}
\multirow{2}{*}{\multicolumn{1}{c|}{ Flux }} & \multicolumn{5}{|c}{$\mathrm{X}$-ray } \\
\cline { 2 - 6 } & $\mathrm{FeK}_{\alpha}$ & $\mathrm{CaK}_{\alpha}$ & $\mathrm{SiK}_{\alpha}$ & $\mathrm{AlK}_{\alpha}$ & $\mathrm{MgK}_{\alpha}$ \\
\hline $\mathrm{Na}_{2} \mathrm{~B}_{4} \mathrm{O}_{7}$ & 1 & 1 & 1 & 1 & 1 \\
$\mathrm{Li}_{2} \mathrm{~B}_{4} \mathrm{O}_{7}$ & 1.39 & 1.49 & 1.45 & 1.47 & 1.42 \\
Fusing mixture & 1.04 & 1.05 & 1.05 & 1.05 & 1.05
\end{tabular}

$$
I_{i}=K^{\prime} \frac{W_{i}}{\mu(i)}=K^{\prime \prime} \frac{1}{f \mu(i)}
$$

where, $f$ : the ratio of dilution, and

$$
W_{i} \propto 1 / f .
$$

Table 1 shows the ratio of fluorescent X-ray intensities of $\mathrm{FeK}_{\alpha}, \mathrm{CaK}_{\alpha}, \mathrm{AlK}_{\alpha}$ and $\mathrm{MgK}_{\alpha}$ from the beads with the aforementioned three reagents, when the ratio of dilution was $1: 10$ and the iron concentration was $60 \%$. As can be seen from this table, lithium borate is most optimum in terms of X-ray intensity, but the choice of the fusing flux in practice depends on the practical usefulness, including the fusing temperature, viscosity at the time of fusion, costs of the fusing flux and others, besides the X-ray intensity.

\section{Study of Removing Additive for Glass Bead}

The most important prerequisite in putting this

Table 2. Comparison of $\mathrm{FeK}_{\beta}$ and $\mathrm{FeK}_{\beta} / \mathrm{CoK}_{\alpha}$ measurements $(\% \mathrm{Fe})$

\begin{tabular}{l|cc} 
& $\mathrm{FeK}_{\beta}$ & $\mathrm{FeK}_{\beta} / \mathrm{CoK}_{\alpha}$ \\
\hline Reproducibility of measurement $\overline{\bar{\sigma}}_{M}$ & 0.08 & 0.21 \\
Accuracy $\overline{\bar{\sigma}}_{d}$ & 0.74 & 0.30
\end{tabular}

Table 3. Fusing conditions in the co-operative inter-

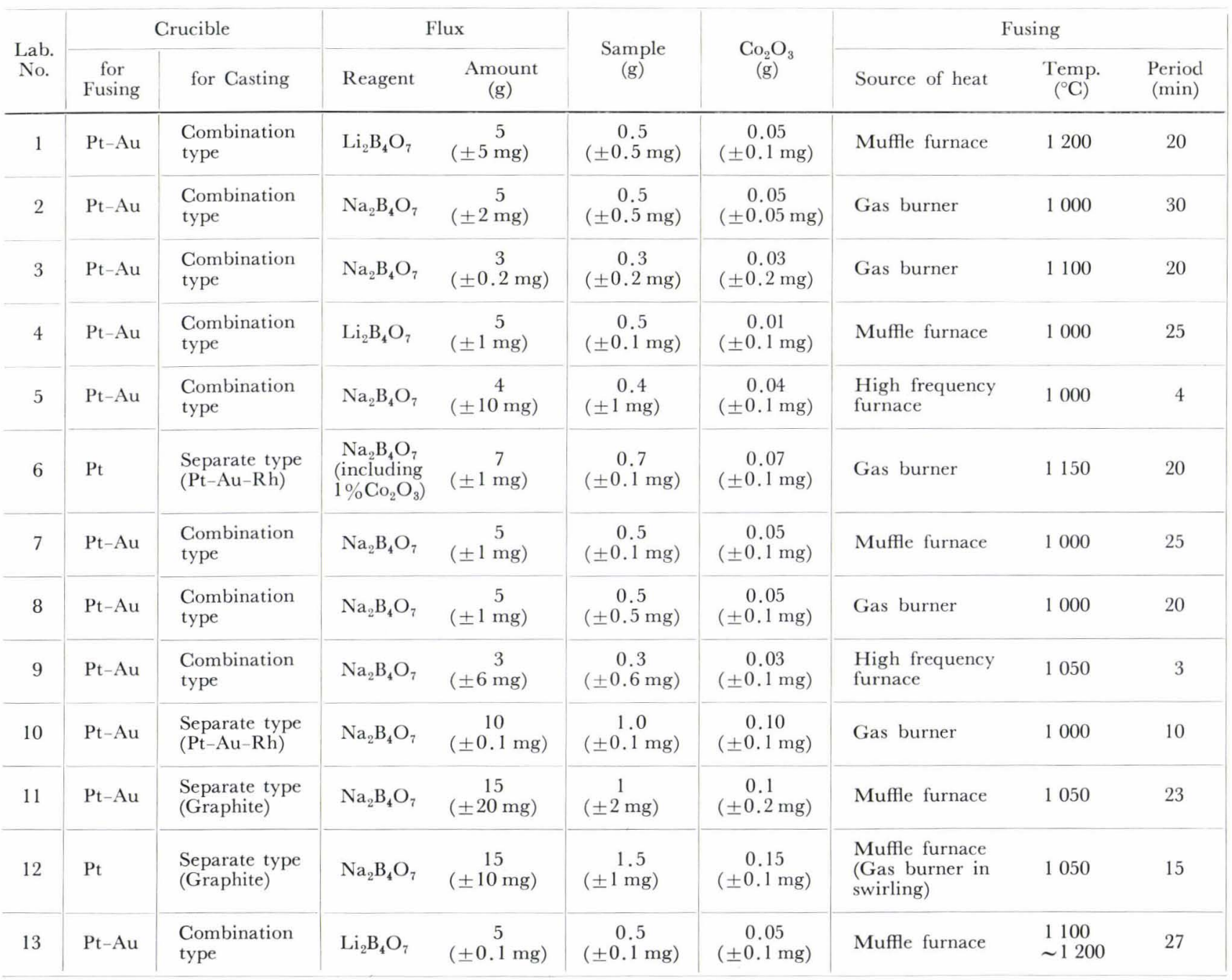


technique to practical use is that satisfactory glass beads can be obtained at all times and that high analytical accuracy can be obtained from the glass bead. Causes for the poor analytical accuracy are varied. One of the major causes is the deformation and the change in quality of the platinum-gold crucible bottom. Although this varies with the type of the heat source used and the heating temperature, this is a symptom observed sooner or later as it is used more often. In such a case, it is difficult to remove the bead from the crucible bottom and, in some cases, cracking of the bead may take place. Even if cracking does not occur, this will make the bottom surface of the bead (analyzing surface) rough and cause the scattering of X-ray, resulting in poor analyzing accuracy. In such a case, the common practice was to remachine or polish the crucible or to shorten the heating time so as to prevent the deformation and the change in quality or to use separate crucibles for fusion and casting. A new approach to solve this problem is the addition of the removing additives. It was found that the addition of a small quantity of $\mathrm{NaBr}, \mathrm{KBr}$ and the like to the fusing flux not only improves the separating property of the bead from the crucible but also makes the upper surface of the bead flat. If an appropriate quantity

laboratory tests

\begin{tabular}{|c|c|c|}
\hline $\begin{array}{l}\text { Swirling to mix } \\
\text { the melt }\end{array}$ & $\begin{array}{c}\text { Bead } \\
\text { repeata- } \\
\text { bility } \\
(\mathrm{C} . \mathrm{V} . \%)\end{array}$ & Remarks \\
\hline 3 times & 0.53 & $\begin{array}{l}0.01 \mathrm{~g} \mathrm{NaBr} \text { is added. The } \\
\text { top surface is measured. }\end{array}$ \\
\hline $\begin{array}{l}\text { once for debubbling } \\
\text { twice for mixing }\end{array}$ & 0.37 & $0.05 \mathrm{~g} \mathrm{NaBr}$ is added. \\
\hline $\begin{array}{l}\text { several times eyery } \\
3 \sim 5 \mathrm{~min}\end{array}$ & 0.25 & \\
\hline continuously & 0.75 & \\
\hline $\begin{array}{l}\text { continuously with } \\
\text { a } \mathrm{Pt}-\mathrm{Au} \text { rod }\end{array}$ & 0.14 & \\
\hline 3 times & 0.23 & \\
\hline $\begin{array}{l}\text { mechanically and } \\
\text { continuously }\end{array}$ & 0.56 & \\
\hline continuously & 0.46 & \\
\hline $\begin{array}{l}\text { by high frequency } \\
\text { inductance }\end{array}$ & 0.75 & \\
\hline 4 times & 0.10 & \\
\hline every $5 \mathrm{~min}$ & 0.003 & \\
\hline $\begin{array}{l}2 \text { times with a gas } \\
\text { burner }\end{array}$ & 0.15 & \\
\hline eyery $5 \mathrm{~min}$ & 0.45 & \\
\hline
\end{tabular}

of additive is added, it is possible to measure the upper surface, which would be too curved to be measured with X-ray spectrometry if the removing additives were not added.

\section{Segregation in the Bead}

To prepare reliable beads it is necessary that the error from one bead to another is small, as a matter of course, and that the bead is free from segregation. To check possible segregation in the bead, the chemical analysis, fluorescent X-ray analysis and electron probe microanalysis were used. The results show that no appreciable segregation of $\mathrm{CaO}, \mathrm{SiO}_{2}$ and $\mathrm{Al}_{2} \mathrm{O}_{3}$ existed in the bead but there was a difference in concentration between the upper and the lower surfaces of the bead and affected the quantitative values of iron and cobalt. There is no research gone deep into the cause, but it seems that this is attributable to the large concentration of iron, which is less liable to vitrify. The difference in concentration can be reduced to such an extent that it does not affect the practical measurement by fusing the bead over again to make it anew. This means that this problem can be overcome by fusing the bead perfectly.

\section{Effect of Cobalt Added on the Determination of Iron in Iron Ore}

For the determination of iron in the iron ore by the fusion technique, it was studied in the co-operative interlaboratory tests whether only the intensity of $\mathrm{FeK}_{\alpha}$ radiation or that of $\mathrm{FeK}_{\beta}$ radiation should be measured or the intensity ratio of $\mathrm{FeK}_{\beta} / \mathrm{CoK}_{\alpha}$ should be measured when $\mathrm{Co}_{2} \mathrm{O}_{3}$ is added. Thirteen laboratories participated in the following manner. Five beads were prepared from the same type of iron ore samples by adding $\mathrm{Co}_{2} \mathrm{O}_{3}$, and $\mathrm{FeK}_{\beta}$ rediations were measured independently five times for each bead to obtain the standard deviation of the masurements at each laboratory, $\sigma_{M}$, (reproducibility). And two beads for each eight JSS standard samples were prepared to obtain the root mean square of the differences between the quantitative values and the standard values at each laboratory, $\sigma_{d}$, (accuracy). Furthermore the averages of all the laboratories, $\bar{\sigma}_{M}$ and $\bar{\sigma}_{d l}$ were calculated. The intensity ratio of $\mathrm{FeK}_{\beta} /$ $\mathrm{CoK}_{\alpha}$ was also measured to obtain the reproducibility and accuracy in the same manner. Table 2 shows the results.

As seen here, the reproducibility of independent measurements of the $\mathrm{FeK}_{\beta}$ radiation is better than that of the intensity ratio of $\mathrm{FeK}_{\beta} / \mathrm{CoK}_{\alpha}$ but the accuracy is lower. This shows that the cobalt internal standard is effective. It was then decided to use the cobalt internal standard method as the standard of operation.

\section{Checking the Reproducibility of Glass Beads}

To prepare glass beads with high accuracy, presumed problems (1) to (4) have been discussed. Some advantages may be expected by introducing these results into the work standard, but there may come 
Table 4. Test results

\begin{tabular}{|c|c|c|c|c|c|c|c|c|c|c|}
\hline & $\mathrm{T} \cdot \mathrm{Fe}$ & $\mathrm{SiO}_{2}$ & $\mathrm{Mn}$ & $\mathrm{P}$ & $\mathrm{Cu}$ & $\mathrm{TiO}_{2}$ & $\mathrm{CaO}$ & $\mathrm{MgO}$ & $\mathrm{Al}_{2} \mathrm{O}_{3}$ & $\mathrm{~S}$ \\
\hline Mean contents (\%) & 62.01 & 5.11 & 0.201 & 0.0806 & 0.0213 & 0.96 & 1.53 & 0.68 & 1.82 & 0.025 \\
\hline$\sigma_{p}$ & 0.32 & 0.068 & 0.0031 & 0.0013 & 0.0025 & 0.014 & 0.014 & 0.048 & 0.032 & 0.0086 \\
\hline$\sigma_{d}$ & 0.30 & 0.075 & 0.0071 & 0.0018 & 0.0039 & 0.015 & 0.023 & 0.046 & 0.048 & 0.0114 \\
\hline C.V. of $\sigma_{d}(\%)$ & 0.48 & 1.5 & 3.5 & 2.2 & 18.3 & 1.6 & 1.5 & 6.8 & 2.6 & 45.6 \\
\hline
\end{tabular}

$\sigma_{M}: \quad \sigma$ of X-ray intensity measurement

$\sigma_{p}: \quad \sigma$ of glass bead preparation

$\sigma_{d}: \quad \sigma$ of difference values between standard values and estimate values

up problems that can not be foreseen due to the differences in temperature, container, stirring method and others at different laboratories. Then discussion was made on the method of judging an unsatisfactory bead. As a result, if the coefficient of variation (C.V. $(\%)$ ) of the $\mathrm{FeK}_{\beta}$ intensity of each bead was below $1 \%$ when the same sample was fused several times in making a bead, the bead was judged to be precise and satisfactory. Details of the practicing method will be described later in the section of the analytical method. The smaller the setting value of the coefficient of variation, the more desirable it is, but co-operative interlaboratory tests were conducted before the values were determined. The minimum of C.V. was $0.1 \%$ and the maximum was $0.62 \%$, whose average was $0.34 \%$. Thus $1 \%$ of C.V. was set, including an extra safety value.

\section{Co-operative Interlaboratory Tests}

Based on the study of these problems and through total co-operative interlaboratory tests, it was intended to confirm the accuracy of this technique and to make it a base in drafting the analytical method. The tests were made to obtain the concentration in each bead from the regression of the average X-ray intensity and standard value, making two beads independently with $\mathrm{Co}_{2} \mathrm{O}_{3}$ added for each of eight JSS standard samples. Prior to these tests, it was confirmed that satisfactory beads were obtained by preparing five beads for a sample and testing the glass beads for adjustment. Table 3 shows the fusing conditions at each laboratory and Table 4 shows the results of the experiments.

As can be seen from Table 4, the relative variation of $\sigma_{d}$ against the average concentration is within $5 \%$, which is satisfactory enough. However, the relative variations for $\mathrm{MgO}, \mathrm{Cu}$ and $\mathrm{S}$ are in excess of $5 \%$. It was decided through the discussion to adopt $\mathrm{MgO}$ and $\mathrm{Cu}$ as applicable components because they are well within the accuracy of the control analysis, but $\mathrm{S}$ was not adopted.

\section{Determination of Analytical Method}

After the discussion and co-operative interlaboratory tests described above, the analytical method of iron ore was drafted. This draft was approved at the 38th Meeting of the Iron and Steel Analysis Committee, Joint Research Society of ISIJ as the ISIJ method. The analytical method is mentioned at the end of this report.

\section{Future Problems}

It was decided at the ISO TC 102/SC2 conference which met in the spring of 1976 to study the fluorescent $\mathrm{X}$-ray analysis by the fusion technique, besides the chemical analysis which had already been well established as a method of analyzing components of iron ore, and the action was initiated partly. It is very significant that the fluorescent $\mathrm{X}$-ray analysis was adopted at this time. Apart from this, there are increasing requirements for the glass bead technique to be applied to the analysis of materials other than iron ore. To meet this situation, it may be necessary to establish a rapid, simple bead preparation technique for a variety of oxides and to study the total absorption correction coefficient $\left(d_{j}\right)$ method for the analysis of oxides. In this sense, the establishment of this method can be regarded as the first step to the practical application of the glass bead technique in industry.

\section{Acknowledgements}

The author would like to thank all the members in the Fluorescent X-ray Analysis Subcommittee and especially the working group members in the Subcommittee for their participation in the co-operative tests and their kind assistance in the preparation of present paper. 


\section{ISIJ (The Iron and Steel Institute of Japan) Iron Ores}

\section{by Bead Technique}

\section{Definition}

The bead technique in this method is defined as follows: the powder sample and fusing reagents are put together in a crucible, fused and cooled to form a glass bead, and the bead thus obtained is analyzed by a fluorescent X-ray spectrometer.

\section{Scope}

This method specifies the analytical procedure for iron ores, sintered ore, oxide pellets and iron sand by means of the bead technique. Constituents to be determined are total iron, silicon dioxide, manganese, phosphorus, titanium dioxide, calcium oxide, magnesium oxide, aluminum oxide and copper. Applicable ranges for respective constituents are shown in Table 1.

\section{Preparation of Beads}

\section{Reagents}

Fusing flux: Anhydrous sodium tetraborate or anhydrous lithium tetraborate.

Internal standard: Cobalt oxide.

\section{Crucibles}

Crucibles to be used are classified into the following two types.

(1) Combination Type

Made of the material that can be hardly deteriorated and deformed. A fusion mixture is fused in the crucible, resulting in the form of a bead in the same crucible. The bead is cooled in the crucible

Table 1. Applicable content ranges

\begin{tabular}{c|c}
\hline Constituents & Content ranges $(\%)$ \\
\hline $\mathrm{T} . \mathrm{Fe}$ & $57.0 \sim 67.0$ \\
$\mathrm{SiO}_{2}$ & $2.0 \sim 14.0$ \\
$\mathrm{Mn}$ & $0.04 \sim 0.5$ \\
$\mathrm{P}$ & $0.02 \sim 0.3$ \\
$\mathrm{TiO}_{2}$ & $0.06 \sim 0.6$ \\
$\mathrm{CaO}$ & $0.05 \sim 9.0$ \\
$\mathrm{MgO}$ & $0.09 \sim 2.0$ \\
$\mathrm{Al}_{2} \mathrm{O}_{3}$ & $0.4 \sim 3.0$ \\
$\mathrm{Cu}$ & $0.008 \sim 0.06$
\end{tabular}

and easily taken out of the crucible (Note (1)).

(2) Separate type

Made of the material that can be hardly deteriorated. A fusion mixture is fused in the crucible for the exclusive purpose of fusion and after fusion the melt is poured into a mould made of the material that can be also hardly deteriorated and deformed. The cooled bead is easily dropped out of the mould.

\section{Procedure for Preparation of Beads}

\section{Weighing}

An ore sample pulverized to pass a $149 \mu \mathrm{m}$ standard sieve, flux and cobalt oxide $\left(\mathrm{Co}_{2} \mathrm{O}_{3}\right)$ in the mass ratio $1:(7 \sim 15): 0.1$ are transferred directly into the crucible. These should be weighed with a precision of $0.2 \%$. Typical amounts are as follow.

Sample $(g): \quad 0.5000 \pm 0.0010$

Flux (g): $\quad 5.0000 \pm 0.0010$

$\mathrm{Co}_{2} \mathrm{O}_{3}(\mathrm{~g}): \quad 0.0500 \pm 0.001$

\section{Fusion and Bead Preparation}

(1) Combination type: The fusion mixture is put in a crucible of the combination use type (III.2. (1)) and fused by a heat source, e.g., a muffle furnace, a Mecker burner, or a high frequency furnace.

A typical fusion temperature is as follows, but the fusion temperature once used should be kept constant all the time.

$$
\begin{array}{ll}
\frac{\text { Flux }}{\mathrm{Na}_{2} \mathrm{~B}_{4} \mathrm{O}_{7}} & \text { Temperature }\left({ }^{\circ} \mathrm{C}\right) \\
\mathrm{Li}_{2} \mathrm{~B}_{4} \mathrm{O}_{7} & 1000 \sim 1050 \\
& 1100 \sim 1150
\end{array}
$$

The fusing period is as follows. The melt is swirled on fusing and bubbles should be removed away.

$\begin{array}{lr}\text { Heat source } & \text { Fusing period (min) } \\ \text { High frequency furnace } & 3 \sim 5 \\ \text { Muffle furnace, Mecker burner } & 20 \sim 25\end{array}$

After melting is completed, the melt is cooled and the bead is taken out of the crucible.

(2) Separate type: The fusion mixture is put in the crucible for the exclusive purpose of melting and fused according to III. 3. 2. (1). The melt is poured into the mould previously heated at $250^{\circ} \sim 400^{\circ} \mathrm{C}$ and cooled. The bead obtained is removed from the mould.

Note (1) The crucible is made from $\mathrm{Pt}-\mathrm{Au}(5 \sim 20 \%)$ alloy or $\mathrm{Pt}-\mathrm{Au}(5 \sim 20 \%)-\mathrm{Rh}(3 \sim 5 \%)$ alloy. Size of the crucible varies according to the amount of the fusion mixture, source of heat and X-ray irradiated area. But, generally optimum size is shown in Fig. 1.

Fig. 1.

Crucible of combination type

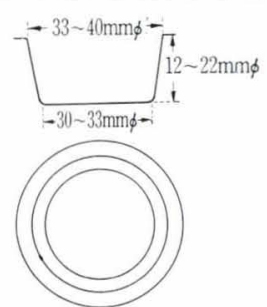


Cobalt oxide is not added in both types of crucibles if iron is not determined.

\section{Check of Beads}

In order to confirm that both fusing technique and the crucible to be used are well qualified, beads are checked in the following way.

Five beads of a standard sample are prepared according to III. 3. The $\mathrm{FeK}_{\beta}$ (or $\mathrm{FeK}_{\alpha}$ when $\mathrm{Co}_{2} \mathrm{O}_{3}$ is not added) intensity of those beads is measured five times independently, and the results are arranged in the form of Table 2.

Then the precision in the bead preparation $\left(\sigma_{p}\right)$ is calculated by Eq. (1) and the bead preparation is checked by Inequality (2).

$$
\begin{aligned}
& \sigma_{p}=\sqrt{\frac{\sum_{i} \sum_{j}\left(X_{i j}-\overline{\bar{X}}\right)^{2}}{(5 \times 5)-1}-\frac{\sum_{i} \sum_{j}\left(X_{i j}-\bar{X}_{i}\right)^{2}}{(5-1) \times 5}} \ldots \ldots(1) \\
& \frac{\sigma_{p}}{\bar{X}} \times 100<1.0 \ldots \ldots \ldots \ldots \ldots \ldots \ldots \ldots \ldots \ldots \ldots \ldots \ldots \ldots \ldots \ldots \ldots \ldots \ldots \ldots \ldots \ldots \ldots \ldots
\end{aligned}
$$

When the beads pass this examination, samples are ready to be analyzed according to $V$. But when the beads do not pass this examination, the fusion conditions should be reexamined. This is repeated until a new series of five beads pass the examination.

\section{Analysis of Unknown Samples}

\section{Analytical Line}

Analytical lines to be used in this method are shown in Table 3 .

$\mathrm{FeK}_{\alpha}$ is used for the check of beads only when $\mathrm{FeK}_{\beta}$ can not be measured.

Table 2. Arrangement of measured intensities

\begin{tabular}{c|ccccc|c}
\hline \multirow{2}{*}{$\begin{array}{c}\text { Bead } \\
\text { No. }(i)\end{array}$} & \multicolumn{5}{|c|}{ Measurement } & \multirow{2}{*}{ No. $(j)$} \\
\cline { 2 - 6 } & 1 & 2 & 3 & 4 & 5 & \\
\hline 1 & $X_{11}$ & $X_{12}$ & $X_{13}$ & $X_{14}$ & $X_{15}$ & $\bar{X}_{1}$ \\
2 & $X_{21}$ & $X_{22}$ & $X_{23}$ & $X_{24}$ & $X_{25}$ & $\bar{X}_{2}$ \\
3 & $X_{31}$ & $X_{32}$ & $X_{33}$ & $X_{34}$ & $X_{35}$ & $\bar{X}_{3}$ \\
4 & $X_{41}$ & $X_{42}$ & $X_{43}$ & $X_{44}$ & $X_{45}$ & $\bar{X}_{4}$ \\
5 & $X_{51}$ & $X_{52}$ & $X_{53}$ & $X_{54}$ & $X_{55}$ & $\bar{X}_{5}$ \\
\hline & & & & & Mean of all values & $\overline{\bar{X}}$ \\
& & & & & &
\end{tabular}

\section{Preparation of Calibration Curve}

Two beads are prepared from each JSS sample (see Table 4) according to III. 3. Fluorescent X-ray intensities of each bead are measured by a fluorescent $\mathrm{X}$-ray spectrometer under its most appropriate conditions. A calibration curve for each element is prepared by plotting the standard value against the mean $\mathrm{X}$-ray intensity of two beads from the same sample. In regard to total iron only, $\mathrm{FeK}_{\beta}$ and $\mathrm{CoK}_{\alpha}$ instead of $\mathrm{FeK}_{\alpha}$ are measured and the intensity ratio of $\mathrm{FeK}_{\beta} /$ $\mathrm{CoK}_{\alpha}$ is plotted in place of the mean $\mathrm{X}$-ray intensities.

\section{Analysis of Unknown Samples}

Beads are prepared from unknown samples according to III. 3 and analyzed by making use of the calibration curves prepared according to V.2. Whenever unknowns are analyzed, the known sample should be analyzed at the same time and the analyzed values are confirmed by the permissible tolerances.

\section{Modification of Calibration Curve}

If test results of the known sample do not fall in the permissible tolerances, make further four beads from the same sample used in $V .3$ and check the five beads according to $I V$. If they pass the examination, the calibration curves should be modified. If they do not pass the examination, the fusing conditions should be reconsidered.

Table 3. Analytical line

\begin{tabular}{l|lccc}
\hline Element & $\begin{array}{c}\text { Analytical } \\
\text { line }\end{array}$ & $\begin{array}{c}\text { Wave- } \\
\text { length } \\
(\mathrm{nm})\end{array}$ & Order & Crystal \\
\hline $\mathrm{Fe}$ & $\mathrm{FeK}_{\beta}$ & 17.57 & 1 & $\mathrm{LiF}$ \\
$\mathrm{Si}$ & $\mathrm{SiK}_{\alpha}$ & 71.26 & 1 & EDDT or PET \\
$\mathrm{Mn}$ & $\mathrm{MnK}_{\alpha}$ & 21.03 & 1 & LiF \\
$\mathrm{P}$ & $\mathrm{PK}_{\alpha}$ & 61.58 & 1 & EDDT or PET or Ge \\
$\mathrm{Cu}$ & $\mathrm{CuK}_{\alpha}$ & 15.42 & 1 & LiF \\
$\mathrm{Ti}$ & $\mathrm{TiK}_{\alpha}$ & 27.50 & 1 & LiF \\
$\mathrm{Ca}$ & $\mathrm{CaK}_{\alpha}$ & 33.59 & 1 & EDDT or LiF \\
$\mathrm{Mg}$ & $\mathrm{MnK}_{\alpha}$ & 98.89 & 1 & ADP or KAP or RAP \\
$\mathrm{Al}$ & $\mathrm{AlK}_{\alpha}$ & 83.38 & 1 & EDDT or PET \\
$\mathrm{Co}$ & $\mathrm{CoK}_{\alpha}$ & 17.90 & 1 & LiF \\
$\mathrm{Fe}$ & $\mathrm{FeK}_{\alpha}$ & 19.37 & 1 & LiF \\
& & & &
\end{tabular}

\begin{tabular}{|c|c|c|c|c|c|c|c|c|c|c|}
\hline JSS No. & Description & T. Fe & $\mathrm{SiO}_{2}$ & Mn & $\mathrm{P}$ & $\mathrm{Cu}$ & $\mathrm{TiO}_{2}$ & $\mathrm{CaO}$ & $\mathrm{MgO}$ & $\mathrm{Al}_{2} \mathrm{O}_{3}$ \\
\hline $\begin{array}{l}800-1 \\
800-2\end{array}$ & Rompin Hematite & 62.85 & 2.61 & 0.22 & 0.042 & 0.064 & 0.09 & 0.02 & 0.22 & 2.01 \\
\hline $\begin{array}{l}801-1 \\
801-2\end{array}$ & Indian Iron Ore & 64.66 & 2.13 & 0.06 & 0.039 & 0.004 & 0.16 & 0.03 & 0.02 & 2.60 \\
\hline $803-1$ & Harmersley Hematite & 62.67 & 5.21 & 0.09 & 0.057 & - & 0.12 & 0.04 & 0.04 & 2.82 \\
\hline $812-1$ & Musan Iron Ore & 60.19 & 14.39 & 0.03 & 0.042 & $(0.0015)$ & 0.06 & 0.63 & 0.46 & 0.40 \\
\hline $813-1$ & Algarrobo Iron Ore & 61.15 & 6.61 & 0.05 & 0.260 & 0.012 & 0.21 & 1.20 & 1.08 & 1.27 \\
\hline $\begin{array}{l}830-1 \\
830-2\end{array}$ & Philippine Iron Sand & 60.53 & 2.27 & 0.61 & 0.125 & 0.011 & 6.37 & 0.66 & 2.18 & 2.74 \\
\hline $\begin{array}{l}850-1 \\
850-2\end{array}$ & Marcona Pellet & 66.76 & 2.56 & 0.04 & 0.017 & 0.015 & 0.09 & 0.37 & 0.73 & 0.48 \\
\hline $851-1$ & Sintered Ore & 57.25 & 5.11 & 0.51 & 0.063 & 0.018 & 0.61 & 9.30 & 0.68 & 2.22 \\
\hline
\end{tabular}

Table 4. JSS standards used for calibration 